\title{
The Human Capital Stock: A Generalized Approach
}

\section{Comment}

\author{
Francesco Caselli and Antonio Ciccone*
}

This draft: March 2018

\begin{abstract}
Jones (2014) examines development accounting with imperfect substitutability between different types of skills. He finds that human capital variation can account for the totality of the variation in income across countries. We show that this amplification of cross-country human capital differences is entirely due to an assumption that the relative wage of skilled workers is solely determined by attributes of workers (once the supply of skilled workers is accounted for). If skill premia are predominantly determined by technology, institutions, and other features of the economic environment, human capital differences explain none of the variation in income per worker.
\end{abstract}

${ }^{*}$ Caselli: London School of Economics, CfM, CEPR (f.caselli@lse.ac.uk). Ciccone: Mannheim University, UPF, Barcelona GSE, CEPR (antonio.ciccone@uni-mannheim.de). We thank Ben Jones, Chad Jones, Federico Rossi, Silvana Tenreyro and two anonymous referees for thoughtful comments. The authors declare that they have no relevant or material financial interests that relate to the research described in this paper. 


\section{Introduction}

How much of the output gap between poor and rich countries can be accounted for by differences in human capital is still debated. One unresolved issue is the role played by imperfect substitutability between different types of human capital. Understanding the role of imperfect substitutability is important, as the seminal contributions in development accounting assume perfect substitutability, but the empirical labor economics literature finds the substitutability between educational attainment levels to be low.

An important recent contribution to development accounting with imperfect substitutability between different types of human capital is due to Benjamin Jones (2014). His aim is to understand how imperfect substitutability changes the results from "traditional" (Jones's terminology) accounting, which treats workers with different educational attainment as perfect substitutes. His main result is that the perfect-substitute case provides a lower bound for the magnitude of human-capital differences across countries, and that, using plausible values for the elasticity of substitution between workers with different educational attainment, measured human capital variation can be boosted to the point that factors of production account for the totality of the variation in income across countries. This finding is in sharp contrast with the previous development accounting literature, which could only

explain about half of the cross-country income variation with production factors, with the other half left to generic efficiency (technology) differences (Klenow and Rodriguez-Clare, 1997; Hall and Jones, 1999; Caselli, 2005).

If differences in human capital could truly account for all the variation in income across countries, as Jones's calculations indicate, the implications would be far reaching. The 
academic and policy debate would have to shift away from its current focus on technology, legal and political institutions, and other features of the economic environment. Instead, the focus should be on the determinants of the skills embedded in workers.

In this comment, we show that the amplification of cross-country human capital differences achieved by Jones, and hence his success at removing the unexplained component of income differences, is entirely due to an assumption that the relative wage of skilled workers is solely determined by attributes of workers (once the supply of skilled workers is accounted for). If, as we argue, skill premia are also influenced by technology, institutions, and other features of the economic environment, cross-country differences in human capital as measured by Jones will embed differences in these technological, institutional, and other attributes. As a result, it is highly unlikely that human capital accounts for all the variation in income across countries. To see how unlikely, we show that if we assume that crosscountry differences in skill premia are driven by technology, institutions, or other features of the environment - instead of being solely driven by attributes of workers - human capital differences go from explaining all cross-country income differences (for plausible values of the elasticity of substitution between workers with different skills) to explaining none.

We build our argument in three parts. In the first part we examine Jones's stated explanation for his finding that relaxing the perfect substitution assumption (greatly) magnifies the cross-country variation in human capital. His explanation focuses on the fact that, when workers with different educational attainment are imperfect substitutes, changes in the educational attainment of the labor force affect the marginal productivity of different skill types. In particular, Jones emphasizes complementarities between skilled and unskilled workers, and that such complementarities imply that the marginal productivity of unskilled 
workers increases when the share of skilled workers increases. Building on the work of Caselli and Ciccone (2013) we show that, contrary to Jones's intuition, the effect of increases in the share of skilled workers on a country's human capital - which we refer to as the relativesupply effect - is always reduced by allowing for imperfect substitution. Hence, it cannot be the effect of skilled workers on the marginal productivity of different skill types that boosts human-capital differences in Jones's calculations.

Our second step, then, is to provide a more accurate intuition for Jones's result that human capital variation can be boosted to the point that factors of production account for the totality of the variation in income across countries. The key observation is that Jones does not merely look at variation in human capital induced by differences in the educational attainment distribution of the labor force, but also at variation in human capital induced by differences in the efficiency units delivered by skilled workers in different countries - a source of variation in human capital which we refer to as the relative-efficiency effect. Since the relative-supply effect on human capital is actually reduced by allowing for imperfect substitution between workers with different educational attainment, Jones's result must entirely be driven by the relative-efficiency effect. We explain intuitively why the relative-efficiency effect on human capital can be greatly increased by allowing for imperfect substitution.

The third step is to understand whether it makes sense to assume that the relative efficiency of skilled workers solely reflects skilled workers' human capital. We see this as a critical issue once it has become clear that Jones's success at boosting estimated potential human-capital variation is due to the relative-efficiency effect.

Jones identifies the relative efficiency of skilled workers across countries from the residual variation in the relative wage of skilled workers once the relative supply of skilled workers is 
accounted for. By assuming that the relative efficiency of skilled workers solely reflects their human capital, Jones therefore implicitly assumes that the relative wage of skilled workers not explained by relative supply solely reflects the human capital of skilled workers. This assumption precludes any role of institutions, technology, and other features of the environment. If the relative wage of skilled workers is partly driven by institutions, technology, or other features of the environment, we cannot interpret the variation in output generated by the relative-efficiency effect as due to human-capital differences.

We also show that if the relative efficiency of skilled workers truly reflected their human capital, some types of skilled workers in rich countries could realize large gains in earnings by moving to poor countries. This is the case no matter how strong complementarities among different types of skilled workers may be. Hence, the virtual absence of skilled migration from rich to poor countries appears to be a challenge to the view that skilled efficiency units are (portable) human capital.

The upshot of the arguments we develop in this comment is that it is not the effect of skilled workers on the marginal productivity of different skill types that magnifies the contribution of human capital in Jones's development accounting with imperfect substitution between skills. Instead, it is that imperfect substitution between skills amplifies cross-country differences in the estimated relative efficiency of skilled workers. Only if we treat the entirety of these efficiency differences as differences in the human capital of skilled workers, can we take Jones's estimated rich-poor gaps in quantified inputs at face value.

Section II clarifies the nature of the thought experiment performed by Jones. Section III offers a more accurate intuition for Jones's result that human capital variation can be boosted by assuming imperfect substitution between skills. Section IV discusses the determinants 
of the relative efficiency of skilled workers as identified by Jones. Section V relates the relative-efficiency effect to previous development-accounting studies. Section VI performs a calculation that, in our opinion, casts some doubt on the plausibility of Jones's interpretation of the relative efficiency of skilled workers as their human capital.

\section{Two Thought Experiments}

Jones explains that his development-accounting results are driven by variation in the marginal product of (imperfectly substitutable) workers with different school attainment associated with differences in the attainment distribution of the labor force. He says: $<<[$ the perfect substitutability] assumption rules out two kinds of effects. First, it rules out the possibility that the marginal product of unskilled workers might be higher when they are scarce ... Second, it rules out the possibility that the marginal product of unskilled workers might be higher through complementarities with skilled workers $>>$ (p. 3754). In other words, rich countries have higher human capital not only because they have more workers who are intrinsically more productive - an effect already captured by the perfect-substitution case but also because unskilled workers are relatively scarce there, and this boosts these workers' marginal productivity. According to Jones, this latter effect, which is only captured when the labor-input aggregator features imperfect substitution, further amplifies the difference in human capital between rich and poor countries.

In a related contribution, Francesco Caselli and Antonio Ciccone (2013) use a similar style of reasoning to reach a seemingly opposite conclusion. They argue that treating workers with different schooling as perfect substitutes yields an upper bound on the magnitude of 
human-capital differences induced by differences in the educational-attainment distribution of the labor force. As they explain, $<<$ an increase in the share of schooled workers has, in general, two types of effects on output. The first effect is that more schooling increases the share of more productive workers, which increases output. $>>$ This is again the standard mechanism already captured in traditional development accounting. $<<$ The second effect is that more schooling raises the marginal productivity of unschooled workers and lowers the marginal productivity of schooled workers. $>>$ This is almost identical to the intuition offered by Jones, except that Caselli and Ciccone additionally point out that the higher marginal productivity of unskilled workers is (potentially) offset by the lower marginal productivity of skilled workers. Indeed, Caselli and Ciccone go on to find that $<<$ when the production function is weakly concave, the increase in the marginal productivity of unschooled workers is more than offset by the decrease in the marginal productivity of schooled workers, $>>$ (p. 200) leading to their conclusion that the perfect-substitution case is an upper bound on differences in human capital induced by differences is schooling.

Why does Jones find that relaxing the perfect substitution assumption (greatly) magnifies the cross-country variation in human capital (and hence income differences explained by factors of production) when Caselli and Ciccone found that variation to shrink? The answer is that, despite the similarity of the verbal reasoning used, the thought experiments performed in the two papers are very different.

For brevity of exposition, we make our points using a labor-input aggregator of the CES form and with only two types of labor

$$
H^{c}=\left[\left(h_{1}^{c} L_{1}^{c}\right)^{\frac{\varepsilon-1}{\varepsilon}}+\left(h_{2}^{c} L_{2}^{c}\right)^{\frac{\varepsilon-1}{\varepsilon}}\right]^{\frac{\varepsilon}{\varepsilon-1}},
$$


where $c$ is a country index, $\varepsilon$ is an elasticity of substitution (the perfect-substitution case is $\varepsilon=\infty) ; H^{c}$ is labor-input per worker; $L_{1}^{c}$ and $L_{2}^{c}$ represent the fraction of the labor force with educational attainment below and above some level (e.g. high school); and $h_{1}^{c}$ and $h_{2}^{c}$ are coefficients that convert bodies into productive services, or the efficiency units delivered by workers of the two types. The appendix extends all of our arguments to the case where there are many types of labor, as in Caselli and Ciccone (2013) and in Jones (2014).

Given the aggregator of labor services in (1), how should we understand the notion of cross-country differences in human capital?

One possibility is to focus on variation in $H^{c}$ induced by differences in the Ls only. Applied to development accounting, this approach to human capital is equivalent to asking how much would a poor country's income increase if it had the relative supplies of skilled and unskilled workers of a rich country. This is the thought experiment in Caselli and Ciccone. It also sounds like the thought experiment in the passages from Jones we quoted in the introduction.

The other possibility is to understand differences in human capital as differences in $H^{c}$ induced by differences in both the Ls and the hs. The thought experiment then asks by how much would the income of a poor country increase if it had the relative supply of skills of a rich country and furthermore poor-country workers delivered the same stream of efficiency units $h_{1}^{c}$ and $h_{2}^{c}$ as rich-country workers. This is actually the thought experiment that Jones engages in. 
More formally, after rewriting (1) as

$$
H^{c}=h_{1}^{c} L_{1}^{c}\left[1+\left(\frac{h_{2}^{c}}{h_{1}^{c}}\right)^{\frac{\varepsilon-1}{\varepsilon}}\left(\frac{L_{2}^{c}}{L_{1}^{c}}\right)^{\frac{\varepsilon-1}{\varepsilon}}\right]^{\frac{\varepsilon}{\varepsilon-1}},
$$

the object of interest in Caselli and Ciccone is

$$
\left.\frac{H^{R}}{H^{P}}\right|_{C C}=\frac{L_{1}^{R}\left[1+\left(\frac{h_{2}^{P}}{h_{1}^{P}}\right)^{\frac{\varepsilon-1}{\varepsilon}}\left(\frac{L_{2}^{R}}{L_{1}^{R}}\right)^{\frac{\varepsilon-1}{\varepsilon}}\right]^{\frac{\varepsilon}{\varepsilon-1}}}{L_{1}^{P}\left[1+\left(\frac{h_{2}^{P}}{h_{1}^{P}}\right)^{\frac{\varepsilon-1}{\varepsilon}}\left(\frac{L_{2}^{P}}{L_{1}^{P}}\right)^{\frac{\varepsilon-1}{\varepsilon}}\right]^{\frac{\varepsilon}{\varepsilon-1}}},
$$

where $R(P)$ is a rich (poor) country. On the other hand, the object of interest in Jones is

$$
\left.\frac{H^{R}}{H^{P}}\right|_{\text {Jones }}=\frac{L_{1}^{R}\left[1+\left(\frac{h_{2}^{R}}{h_{1}^{R}}\right)^{\frac{\varepsilon-1}{\varepsilon}}\left(\frac{L_{2}^{R}}{L_{1}^{R}}\right)^{\frac{\varepsilon-1}{\varepsilon}}\right]^{\frac{\varepsilon}{\varepsilon-1}}}{L_{1}^{P}\left[1+\left(\frac{h_{2}^{P}}{h_{1}^{P}}\right)^{\frac{\varepsilon-1}{\varepsilon}}\left(\frac{L_{2}^{P}}{L_{1}^{P}}\right)^{\frac{\varepsilon-1}{\varepsilon}}\right]^{\frac{\varepsilon}{\varepsilon-1}}},
$$

where we have followed Jones, who for the most part assumes that the $h$ s of unskilled workers are the same across countries, $h_{1}^{R}=h_{1}^{P} \cdot{ }^{1}$ Both formulas ask what would be the proportional increase in human capital (and thus, once plugged into a full developmentaccounting framework, in income) if the poor country had the relative supply of skilled workers of the rich country. This is the relative-supply effect. In addition, Jones's formula simultaneously changes the relative efficiency of skilled workers in the poor country from the poor-country value $h_{2}^{P} / h_{1}^{P}$ to the rich-country value $h_{2}^{R} / h_{1}^{R}$. This is the relative-efficiency

\footnotetext{
${ }^{1}$ Jones maintains this assumption in his main development-accounting calculations, because $h_{1}^{c}$ remains unobservable in his framework (whether directly or indirectly), but also presents some robustness checks. The assumption seems fairly innocuous to us for Jones's purposes, as in the case $h_{1}^{R} \geq h_{1}^{P}$ - which surely is the plausible assumption under Jones's human-capital interpretation of the $h \mathrm{~s}-(4)$ presents a lower bound on the answer to his thought experiment. Put differently, human capital, as Jones defines it, would account for even greater differences in income across countries if $h_{1}^{R}>h_{1}^{P}$.
} 
effect.

It is immediate from Jones's object of interest in (4) that the larger the relative efficiency of rich countries $h_{2}^{R} / h_{1}^{R}$ compared to the relative efficiency of poor countries $h_{2}^{P} / h_{1}^{P}$, the larger the ratio $H^{R} / H^{P}$. Hence, the larger the rich-poor gap in the relative efficiency of skilled workers, the greater the increase in human capital as Jones defines it.

In (3) and in (4), the fractions of the labor force that are skilled and unskilled are, in principle, directly observable (from data on educational attainment), but $h_{2}^{P} / h_{1}^{P}$ and $h_{2}^{R} / h_{1}^{R}$, the relative efficiencies of skilled workers in poor and rich countries, are not. In order to implement (3) and (4), we follow Jones, who in turn uses the method proposed by Caselli and John Coleman (2006). If $H^{c}$ in (1) enters the production function for aggregate output and workers are paid their marginal product in the rich and the poor country, we have

$$
\frac{w_{2}^{c}}{w_{1}^{c}}=\left(\frac{h_{2}^{c}}{h_{1}^{c}}\right)^{\frac{\varepsilon-1}{\varepsilon}}\left(\frac{L_{2}^{c}}{L_{1}^{c}}\right)^{-\frac{1}{\varepsilon}}
$$

where $w_{i}^{c}$ is the average wage received by a worker with skill $i$ in country $c$. Using (5) we can infer the unobservable $\left(h_{2}^{c} / h_{1}^{c}\right)^{(\varepsilon-1) / \varepsilon}$ from country-specific data on the relative wage of skilled workers $w_{2}^{c} / w_{1}^{c}$, relative labor supplies $L_{2}^{c} / L_{1}^{c}$, and a choice for the value of the elasticity of substitution $\varepsilon$. These estimates for $\left(h_{2}^{c} / h_{1}^{c}\right)^{(\varepsilon-1) / \varepsilon}$ can then be plugged into the two different thought experiments in (3) and (4). ${ }^{2}$

To find the answers to the two thought experiments we use the same data as Jones and define the unskilled group as he does, namely as all workers with primary schooling or less. All other workers are high skill. To compute the relative wage of skilled workers (the skill

\footnotetext{
${ }^{2}$ Malmberg (2018) proposes an alternative method to estimate $h_{2}^{c} / h_{1}^{c}$ using trade data.
} 
premium), again we follow Jones's method for imputing a country-specific wage to each educational attainment category we observe in the data, and then define the relative wage of skilled workers as the average wage of skilled workers divided by the average wage of unskilled workers.

Table 1, which is modelled on Jones's Table 2, shows the results from the two sets of calculations in (3) and (4). The table reports the ratio of "human capital" in the countries at the 85 th and the 15 th percentile of the distribution of income per worker for various values of the elasticity of substitution $\varepsilon$. Following Jones, we only consider values $\varepsilon>1$, as values less than one are considered implausible in the empirical literature. ${ }^{3}$

Table 1: The Role of Relative Efficiency in Jones's Development Accounting

\begin{tabular}{lccccccc}
\hline & \multicolumn{7}{c}{ Elasticity of Substitution } \\
\hline & 1.2 & 1.4 & 1.5 & 1.6 & 1.8 & 2 & $\infty$ \\
\hline$H^{85} / H^{15}$ from (3) & 0.9 & 1.0 & 1.0 & 1.0 & 1.1 & 1.2 & 2.1 \\
$H^{85} / H^{15}$ from (4) & 316.8 & 20.4 & 11.7 & 8.1 & 5.2 & 3.9 & 1.3 \\
\hline
\end{tabular}

Note to table: "Human capital" ratios between countries at the $85^{\text {th }}$ and $15^{\text {th }}$ percentiles of the income distribution using only the relative-supply effect (top row) and both the relative-supply and relative-efficiency effects (bottom row).

The first row of Table 1, which shows the results based on (3), confirms Caselli and Ciccone's result that the increase in human capital due to the relative-supply effect is bounded above by the case where different types of labor are perfect substitutes $(\varepsilon=\infty){ }^{4}$ It can also be seen that the relative-supply effect on human capital becomes weaker as the two types of labor become less substitutable. ${ }^{5}$ Most important for development accounting, the cross-

\footnotetext{
${ }^{3}$ We use the same values of the elasticity of substitution as Jones, except that we add an extra column for $\varepsilon=1.5$, as this value of the elasticity of substitution is very close to a consensus among researchers.

${ }^{4}$ Caselli and Ciccone show this to be true for any number of skill types and any pattern of substitutability/complementarity among different skill types as long as the human capital aggregator is weakly concave in workers of different skill types.

${ }^{5}$ The reason why (3) drops below unity for $\varepsilon=1.2$ is that in this case, assigning the relative supply of
} 
country variation in human capital due to the relative-supply effect is always rather small: even the largest ratio is small compared to differences in income and, as Caselli and Ciccone (and several others before them) show, it implies large unexplained income differences.

The bottom row of Table 1 presents development accounting a la Jones, based on (4), and is directly comparable to the first row of his Table 2. Indeed, although we use a version with only two skill types, quantitatively our figures are remarkably close to Jones's. As in Jones's table, the lower the elasticity of substitution, the larger the ratio of rich to poor human capital as Jones defines it.

The fact that the rich-poor human capital ratios increase as the elasticity of substitution declines illustrates Jones's result that the perfect-substitution case is a lower bound on the explanatory power of human capital for cross-country income differences when human capital is defined to include both the relative-supply and the relative-efficiency effects. Indeed the large values for the rich-poor human capital ratio in the neighborhood of $\varepsilon=1.5$ are the basis for Jones's conclusion that one can explain all of the cross-country income gap with inputs alone. ${ }^{6}$

skilled and unskilled workers of rich countries to poor countries would lead to the marginal productivity of skilled workers dropping below the marginal productivity of unskilled workers in poor countries. This would not happen if skilled workers could do unskilled jobs and were as productive as unskilled workers in doing these jobs. However, our calculations assume that skilled workers are restricted to do skilled jobs for simplicity.

${ }^{6}$ While Jones's main empirical results are based on equation (4), or its equivalent for many skill types, his main theoretical results involve a somewhat different object, denoted $\Lambda$, which he interprets as the proportional error made by traditional accountants when assuming that different skills are perfectly substitutable. In particular, his Lemma 2 gives a condition on the $h \mathrm{~s}$ and the $L \mathrm{~s}$ under which this error is greater than 1 (i.e. traditional development accounting underestimates human-capital differences). This condition is also sufficient for (4) and (5) evaluated at $\varepsilon<\infty$ to exceed (4) and (5) evaluated at $\varepsilon=\infty$. But it is not sufficient for (3) and (5) evaluated at $\varepsilon<\infty$ to exceed (3) and (5) evaluated at $\varepsilon=\infty$. In fact we know from Caselli and Ciccone that (3) and (5) evaluated at $\varepsilon<\infty$ is always less than (3) and (5) evaluated at $\varepsilon=\infty$. We point this out because the condition stated in Jones's Lemma 2 allows values of the $h$ s and $L$ s under which (3) and (4) are identical and this may appear to generate a contradiction between the theoretical results in Jones and in Caselli and Ciccone. The fact that Jones's question in (4) involves the relative efficiency of rich countries and that he infers this relative efficiency from the skilled wage premia in rich countries using (5) resolves this seeming contradiction. 


\section{Imperfect Substitution and the Relative-Efficiency}

\section{Effect}

In the previous section we have seen that the less substitutable workers with different skills are deemed to be, the smaller the human-capital differences that can be attributed to differences in the relative supply of workers with different skills. Hence, Jones's emphasis on this relative-supply mechanism does not truly convey the intuition for the amplification in human-capital differences that he obtains when assuming that workers with different skills are imperfect substitutes. The purpose of this section is to provide a more accurate intuition.

We have also seen that, alongside with the relative-supply effect, Jones's thought experiment includes a relative-efficiency effect. Since the relative-supply effect implies smaller human-capital differences as the elasticity of substitution declines, it is obvious that it is the relative-efficiency effect that causes human-capital differences to increase as the elasticity of substitution declines in Jones's calculations. Hence, to understand why human-capital differences, as Jones defines them, increase when the elasticity of substitution falls, we need to ask why the relative-efficiency effect becomes more powerful at lower values of the elasticity of substitution between skilled and unskilled workers. As the empirically relevant case is where the elasticity of substitution $\varepsilon$ is greater than unity, we will focus on lowering $\varepsilon$ conditional on $\varepsilon>1$.

Recall that the relative-efficiency effect is associated with the fact that we have $h_{2}^{R} / h_{1}^{R}$ in the numerator and $h_{2}^{P} / h_{1}^{P}$ in the denominator of Jones's human-capital increase $H^{R} / H^{P}$ in (4). In particular, the larger the rich-poor gap in $h_{2}^{c} / h_{1}^{c}$, the larger the ratio $H^{R} / H^{P}$. Evidently, therefore, what happens is that the less substitutable are workers with different 
skills, the larger the gap between $h_{2}^{R} / h_{1}^{R}$ and $h_{2}^{P} / h_{1}^{P}$.

Caselli and Coleman (2006) explain why the gap between $h_{2}^{R} / h_{1}^{R}$ and $h_{2}^{P} / h_{1}^{P}$ increases when the elasticity of substitution declines. Recall that $h_{2}^{c} / h_{1}^{c}$ is backed out from (5) using cross-country data on relative wages and the educational-attainment distribution of the labor force. In the data, $L_{2}^{c} / L_{1}^{c}$ is much higher in rich countries, which would imply lower relative wages for skilled workers if the (negatively sloped) relative demand function for skilled workers was the same in rich and poor countries. How much lower the implied relative wage of skilled workers in rich countries should be depends on the assumed slope of the relative demand function for skilled workers. As lower values of $\varepsilon$ in (5) correspond to a steeper relative demand function for skilled workers, the difference between the relative wage of skilled workers in rich and in poor countries should become larger and larger as the value of $\varepsilon$ falls. However, empirically, relative wages of skilled workers across countries are only mildly decreasing in the relative supply of skilled workers, so the gap between the actual difference in relative wages and the difference predicted under the assumption that all countries have the same relative demand function for skilled workers becomes larger and larger as $\varepsilon$ declines.

The role of $h_{2}^{c} / h_{1}^{c}$ in (5) is to reconcile observed relative wages with observed relative supplies of skilled workers. Clearly, then, since observed relative supplies predict lower relative wages of skilled workers in rich countries compared to poor countries when $\varepsilon$ falls, larger differences between $h_{2}^{R} / h_{1}^{R}$ and $h_{2}^{P} / h_{1}^{P}$ are needed (conditional on $\varepsilon>1$ ) to match observed relative wages. This is why the relative-efficiency effect becomes stronger as $\varepsilon$ declines.

The economics behind this mechanism is simple. Rich countries have a much greater 
relative supply of skilled workers, so, to explain why the relative wage of skilled workers is not much lower there, it must be that skilled workers deliver more relative efficiency units $h_{2}^{c} / h_{1}^{c}$ in rich than in poor countries (again, conditional on $\varepsilon>1$ ). The lower $\varepsilon$, the more precipitous the predicted decline in the relative wage of skilled workers in rich compared to poor countries, and the larger the increase in the relative efficiency of skilled workers required to make sense of the relative flat empirical profile of skill premia across countries.

Summarizing, Jones's development accounting is so strikingly successful because the more imperfectly substitutable workers with different skills, the larger the cross-country differences in the relative efficiency of skilled workers required to explain the relative wage of skilled workers. And the larger the differences in the relative efficiency of skilled workers, the larger the cross-country differences in human capital, because Jones defines it to include all of the cross-country variation in relative efficiency. ${ }^{7}$

\section{What Does Relative Efficiency Capture?}

We have seen that Jones's thought experiment asks by how much the human capital of poor countries (and hence their income) would increase if poor countries had both the relative supply of skilled workers and the relative efficiency of skilled workers of rich countries. Relative efficiency is identified from the relative wage of skilled workers not accounted for by the relative supply of skilled workers. As Jones interprets the relative efficiency of skilled workers as their human capital, this implies that he is assuming that the human capital of

\footnotetext{
${ }^{7}$ Throughout the paper Jones makes virtually no mention of the role of induced estimates of relative efficiency units, which we have argued to be the real source of his result. Only towards the very end of the paper (page 3769), Jones does mention the sensitivity of implied relative efficiencies to the elasticity of substitution, but gives no hint that this is actually the crucial driver of his results.
} 
skilled workers explains all of the relative wage of skilled workers that cannot be accounted for by relative supply.

The human capital of a worker is generally seen as a function of his or her personal attributes, including years of schooling, cognitive ability, experience, health, energy, ambition, integrity etc. It is well understood that such attributes influence wages. But Jones's interpretation of relative efficiency as human capital implicitly assumes that skill premia not accounted for by skill supply reflect solely such attributes of workers.

However, it seems extremely implausible that attributes of workers are the sole determinant of skill premia not accounted for by skill supply. Instead, it seems very likely that skill premia are also shaped by institutions, technology, organizational structures, infrastructure, the structural composition of the economy, openness to trade, social norms, and other attributes of the environment.

An example of an attribute of the environment that affects skill premia not accounted for by skill supply is the skill bias of technology. If rich countries use robots operated by highly skilled engineers, while poor countries use traditional assembly lines manned by low-skill workers, then rich countries will have a higher $h_{2}^{c} / h_{1}^{c}$ even if the human capital of engineers is the same in poor and rich countries (Caselli and Coleman, 2006; Caselli, 2017). As Jones's approach assumes that skill premia are fully explained by the relative human capital of skilled workers and skill supply, it leaves no role for skill-biased technology. This contrasts with the evidence that the skill bias of technology plays a role for the relative wages of skilled workers conditional on their relative human capital and supply (e.g. Katz and Murphy, 1992; Machin and van Reenen, 1998; Autor, Katz, and Kearney, 2008).

Another example of an attribute of the environment that affects skill premia is openness 
to international trade. As is well understood, trade openness determines the extent to which countries can specialize in production and - through the distributive effects of specialization - relative factor prices, including the relative wage of skilled workers. Trade openness also affects the relative price of capital goods, which has been found to shape skill premia due to capital-skill complementarities (Krusell at al., 2000). Finally, the skill bias of technology in a country is also determined by the trade openness of other countries through the effect of global trade openness on the incentives to develop skill-complementary technologies (Acemoglu, 2003).

A third example of an attribute of the environment that affects skill premia is the quality of contract enforcement. Countries with better contract enforcement tend to specialize in the production of sectors where relationship-specific investments are more important, and these sectors are also more skill intensive (Nunn, 2007). Hence, better contract enforcement results in a greater relative demand for skilled workers and higher skill premia. One could give many other examples where skill premia are affected by features of the environment. ${ }^{8}$

If, as we argue, differences in institutions, technology, organizational structures, etc. are a contributing factor behind skill premia, then it is no longer legitimate to regard the thought experiment performed by Jones as measuring the contribution of human capital to crosscountry income differences. This is because the thought experiment now involves assigning to poor countries not only the schooling and other personal attributes of workers in rich

\footnotetext{
${ }^{8}$ Of course, the skill bias of technology, openness to international trade, or judicial quality - and indeed other features of the environment responsible for cross-country differences in skill premia - could be partially endogenous to human capital. But this could not possibly justify treating all of the effects of skill-biased technology, trade openness, and judicial quality on skill premia as human capital. After all, even in traditional development accounting, differences in total factor productivity could be partially endogenous to the measure of schooling used to construct human capital (e.g. Nelson and Phelps, 1966), and yet to our knowledge nobody has suggested that differences in total factor productivity should be interpreted as differences in human capital.
} 
countries, but also the technology, institutions, and other features of the environment of rich countries that determine skill premia. ${ }^{9}$

Some readers may be tempted to say: <<it's just a label - who cares how you call it? > > But imagine a world where $L_{1}^{R}=L_{1}^{P}, L_{2}^{R}=L_{2}^{P}$, and $h_{1}^{R}=h_{1}^{P}$, so that all variation in $H^{c}$ came from differences in $h_{2}^{c}$. Imagine further that you knew that all differences in $h_{2}^{c}$ came from institutions for example. Jones's development-accounting approach applied to this world would conclude that all of the variation in income across countries is explained by human capital. This conclusion feels clearly misleading.

To see how sensitive the implications for development accounting could be to the interpretation of the $h \mathrm{~s}$, it is useful to return to the results in our Table 1 . We already know that the results in the second row for values of $\varepsilon$ around 1.5 are the basis for Jones's striking success in development accounting. We also know that this success is driven by Jones's assumption that the relative efficiency of skilled workers is equal to their human capital. What if we instead take the alternative view that cross-country differences in the relative efficiency of skilled workers are driven by institutions, technology, and other features of the environment? ${ }^{10}$ In this case, the counterfactual increase in human capital in poor countries

\footnotetext{
${ }^{9}$ The distinction between attributes of the worker (part of human capital) and attributes of the environment (not part of human capital) is implicit in the work of Lutz Hendricks (2002), Todd Schoellman (2012), and Hendricks and Schoellman (2017) among others, who have used changes in wages upon migration to distinguish between differences in total factor productivity and differences in human capital (not captured by educational attainment). Applying their style of reasoning to the present context, if we saw a worker with attainment $i$ providing $h_{i}^{c}$ efficiency units in country $c$, and then suddenly providing $h_{i}^{c^{\prime}}$ units upon moving to country $c^{\prime}$, we would conclude that it is the environment of country $c^{\prime}$ that has increased the efficiency units provided by this worker, and not that this worker's human capital has increased. This is another way to see that it is inappropriate to assume that all differences in $h$ must be interpreted as differences in human capital, as Jones implicitly does.

${ }^{10}$ This alternative view allows for skill premia to also reflect the human capital of skilled workers (and is therefore less extreme than Jones's implicit assumption that the environment plays no role at all for skill premia, as these are solely determined by the human capital of skilled workers). But the human capital of skilled workers is taken to be the same across countries. Formally, suppose that relative efficiency can be written as $h_{2}^{c} / h_{1}^{c}=\left(e_{2}^{c} / e_{1}^{c}\right)\left(s_{2}^{c} / s_{1}^{c}\right)$ where $e_{2}^{c} / e_{1}^{c}$ captures the relative efficiency of skilled workers due to
} 
is actually given by the results in the first row of Table 1 , as these assume that the efficiency units of poor-country workers with different educational attainments remain unchanged in the thought experiment. These results indicate that human capital can't account for any differences in income across countries for values of $\varepsilon$ around 1.5 !

\section{Relative Efficiency and Traditional Development Ac-}

\section{counting}

It is possible to argue that development accounting with perfect substitution between different skills (traditional accounting in Jones's terminology) includes a relative-efficiency effect on human capital. But a perusal of the literature (Hall and Jones, Klenow and RodriguezClare, Caselli) suggests to us that, to the extent that a relative-efficiency effect on human capital was included, this inclusion was accidental. The likely reason for the accidental inclusion of the relative-efficiency effect is that, under perfect substitution, it is inconsequential quantitatively. This is because under perfect substitution, the relative efficiency of skilled workers is given by the relative wage of skilled workers, as (5) reduces to $w_{2}^{c} / w_{1}^{c}=h_{2}^{c} / h_{1}^{c}$, and relative wages of skilled workers do not vary much between rich and poor countries. As a result, it doesn't matter much quantitatively whether development accounting is done with or without a relative-efficiency effect on human capital. An example of this can be seen in our Table 1, where with $\varepsilon=\infty$ human capital ratios are small compared to cross-country income differences, whether attainment levels in rich countries are aggregated using the skill

attributes of the environment and $s_{2}^{c} / s_{1}^{c}$ captures the relative efficiency of skilled workers due to human capital. Jones's implicit assumption (and the assumption in the second row of Table 1 ) is that $e_{2}^{c} / e_{1}^{c}=1$. The assumption in the first row of Table 1 is that $s_{2}^{c} / s_{1}^{c}=s_{2} / s_{1}$. 
premia in poor countries (in the first row) or in rich countries (in the second row). ${ }^{11}$

It is only once one moves away from perfect substitution among workers with different skills, of course, that the data starts indicating substantial differences in the relative efficiency of skilled workers across countries, for the reasons explained by Caselli and Coleman (2006) and summarized above. This is why with imperfect substitution it becomes important to take a stand on the extent to which relative efficiency captures human capital and the extent to which relative efficiency captures institutions, technology, and other features of the environment. Indeed both Caselli and Coleman (2006) and Caselli and Ciccone (2013), who, like Jones, consider development accounting under imperfect substitution, recognized this challenge, and decided that it would be inappropriate to ascribe the relative efficiency effect to human capital, without further evidence. ${ }^{12}$

These observations also help explain why, in Section II, when considering development accounting under imperfect substitution, we have found it useful to slightly recast the development-accounting question. Development accounting is usually conceptualized as an exercise in variance (or interpercentile range) decomposition, i.e. as asking how much of the variation in income across countries is accounted for by variation in inputs. One implication of the discussion so far is that this question becomes impossible to answer when inputs

\footnotetext{
${ }^{11}$ Indeed the table tells us that under perfect substitution the relative-efficiency effect on human capital goes in the direction of reducing, rather than amplifying, rich-poor human capital ratios. This is because educational wage premia are (mildly) lower in rich countries, and this implies, under perfect substitution, that the relative efficiency of workers with higher educational attainment is higher in poor countries - a paradoxical implication that underscores our point about the accidental nature of the inclusion of the relative-efficiency effect on human capital in traditional accounting.

${ }^{12}$ Caselli and Coleman (2006) discuss the possible human-capital interpretation of the relative-efficiency term but find an interpretation based on skilled-biased technology more plausible. Caselli and Ciccone (2013) acknowledge that we cannot say how much of the relative-efficiency differences are due to human capital or to features of the environment. From this, they conclude that, with the current knowledge, development accounting with imperfect substitution cannot really hope to measure human capital differences. Thus, they settle on the more modest goal of measuring only those differences in human capital that are induced by differences in years of schooling.
} 
are non-separable bundles of input quantities and terms that are potentially attributable to institutions, technology, or other features of the environment (such as $h_{1}^{c}$ and $h_{2}^{c}$ in (1)). However, it is still possible to answer a slightly modified formulation of the developmentaccounting question: by how much would income increase in poor countries if the quantities of certain inputs increased to rich-country values? For example, equation (3) does not aim to measure human capital, or compare human capital across countries, as in the standard conceptualization of the development-accounting question. Instead, it asks about the impact

on income of changing the educational attainment of the labor force, holding constant both the human capital associated with different educational achievements and the institutional and technological determinants of the productivity of different groups. While this way of framing the question is different from the usual one, we see it as entirely in line with the scientific and policy motivations that led to this literature to begin with.

\section{An Implication of Treating Relative Efficiency as Human Capital}

In the previous section we argued that Jones's conclusion that inputs into production have the potential to explain the entirety of cross-country differences in income is a consequence of his identification of the relative efficiency of skilled workers with these workers' human capital. We now point out an implication of this assumption which, we argue, seems prima facie at odds with the patterns of international labor migration. In particular, we perform some basic calculations to bring out the order of magnitude of wage gains or losses for skilled 
workers moving from a rich to a poor country.

Consider an aggregate production function, as in Jones quantitative work, of the form

$$
Y^{c}=A^{c}\left(K^{c}\right)^{\alpha}\left(H^{c}\right)^{1-\alpha}
$$

where $Y^{\mathbf{c}}$ denotes output per worker, $K^{\mathbf{c}}$ denotes physical capital per worker, $A^{\mathbf{c}}$ denotes total factor productivity, and $\alpha$ the elasticity of output with respect to physical capital. $H_{c}$ continues to be defined as in (1). In particular, this means that there is one type of skilled labor only. In the appendix we extend our approach to the case of an arbitrary number of skilled-labor types and any pattern of substitutability/complementarity among different skilled-labor types.

Given (6), we compute gains from skilled-labor migration in two different ways. First, assuming that the relative efficiency of skilled workers solely reflects their human capital, as Jones does. Second, assuming that cross-country differences in the relative efficiency of skilled workers are solely driven by institutions, technology, and other features of the environment. $^{13}$ Wage gains or losses will turn out to be very different under these two interpretations, because the skilled worker would take her human capital with her, but would have to adopt the destination country's environment.

Suppose that workers are paid their marginal product in the rich as well as the poor country. If a skilled worker moves from a rich country to a poor country, and $h$ is an attribute of the worker, then the wage in the destination country relative to the wage in the

\footnotetext{
${ }^{13}$ As already mentioned, this interpretation allows for skill premia to also reflect the human capital of skilled workers. See footnote 9 .
} 
country of origin is

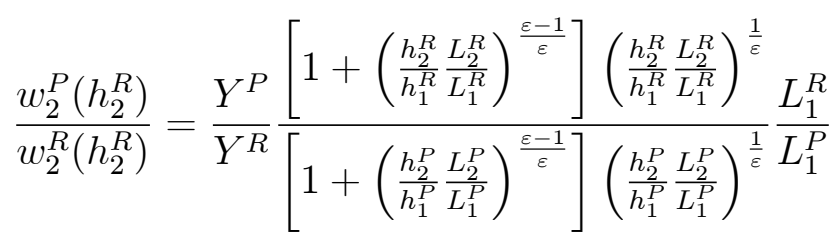

where $w_{2}^{c}(h)$ is the wage received in country $c$ by a skilled worker with human capital $h$. We continue to assume, as Jones does in his main quantitative work, that $h_{1}^{P}=h_{1}^{R} \cdot{ }^{14}$

If, instead, we treat cross-country differences in the relative efficiency of skilled workers as an attribute of the environment, then the wage in the destination country relative to the wage in the country of origin for a rich-country skilled worker migrating to a poor country is

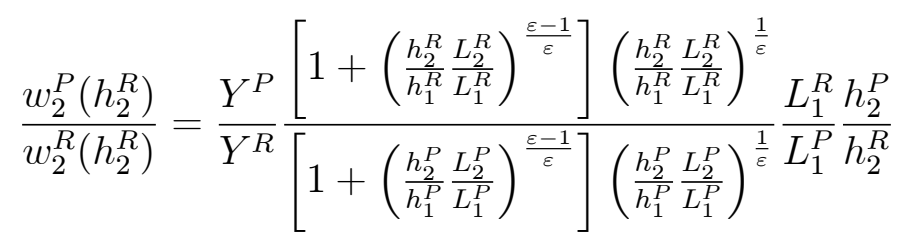

which differs from the case where the $h$ s are attributes of the worker by the last term, $h_{2}^{P} / h_{2}^{R} \cdot{ }^{15}$

In order to quantify the wage gains or losses of skilled-worker migration from rich to poor countries implied by (7) and (8), we need relative GDP per worker $Y^{P} / Y^{R}$; the fraction of the labor force that are skilled and unskilled in the poor and in the rich country; relative within-country efficiencies $h_{2}^{c} / h_{1}^{c}$; and (for (8) only) relative between-country skilled labor efficiencies $h_{2}^{P} / h_{2}^{R}$. Relative GDPs are readily available in the Jones dataset, and everything

\footnotetext{
${ }^{14}$ This assumption should be fairly innocuous for our purposes, as it can readily be shown that if $h_{1}^{R} \geq h_{1}^{P}$ - which is the plausible assumption under the human capital interpretation of $h$ - our expression in (7) is a lower bound on the wage gain for a skilled rich-country worker moving to the poor country.

${ }^{15}$ These calculations abstract from any adjustment costs or lack of transferability of skills across countries. However the magnitudes of the wage gains under (7) is such that it is hard to see how such costs would negate the gains from migration.
} 
else has already been estimated above.

Table 2: The Gains from Skilled Migration to Poor Countries

\begin{tabular}{lccccccc}
\hline & \multicolumn{7}{c}{ Elasticity of Substitution } \\
\hline & 1.2 & 1.4 & 1.5 & 1.6 & 1.8 & 2 & $\infty$ \\
\hline Gain from (8) & 0.14 & 0.14 & 0.14 & 0.14 & 0.14 & 0.14 & 0.14 \\
Gain from (7) & 23659.21 & 42.80 & 12.10 & 5.21 & 1.82 & 0.97 & 0.08 \\
\hline
\end{tabular}

Note to table: Wage gain or loss for skilled workers moving from the country at $85^{\text {th }}$ to the country at $15^{\text {th }}$ percentile of the income distribution when $h$ is an attribute of the environment (top row) and when it is an attribute of the workers (bottom row)

Table 2 reports the wage in the destination country relative to the wage in the country of origin for a skilled worker migrating from a rich to a poor country calculated using (7) and (8) for different values of the elasticity of substitution. The top row shows results using (8), which assumes that cross-country differences in the relative efficiency of skilled workers are solely driven by institutions, technology, and other features of the environment. We see that there is a considerable wage loss and hence little incentive for skilled workers to move from rich to poor countries. ${ }^{16}$ The bottom row shows results using (7), which assumes that the relative efficiency of skilled workers solely reflects attributes of the workers. The wage gains for rich-country skilled workers who move to poor countries are now large for virtually any plausible elasticity of substitution. And note that these are just the wage gains from moving from the 85th percentile of the income distribution (Israel) to the 15th (Kenya). The wage gains from moving from the US to Kenya are even bigger. Given these large gains, we would expect to observe significant rich-to-poor migration of skilled workers. That skilled labor flows almost exclusively from poor to rich countries seems evidence against interpreting $h$ as

\footnotetext{
${ }^{16}$ Using the formula for $h_{2} / h_{1}$ in terms of the relative wage and the relative labor supplies shows that the estimated gains are independent of the choice of $\varepsilon$.
} 
an attribute of workers.

In the appendix, we extend our argument to the case of an arbitrary number of skilledlabor types and any pattern of substitutability/complementarity among different skilledlabor types. Using reasoning analogous to the case with one type of skilled labor above, we show that the wage gains in Table 2 can be reinterpreted as wage gains for a representative group of skilled-labor types moving from the rich to the poor country. Of course, this implies that there must be one or more skilled-labor types that would reap at least the wage gain in Table 2 by moving from the rich to the poor country, no matter what the pattern of substitutability/complementarity among different skilled-labor types may be. This appears inconsistent with all types of skilled labor flowing almost exclusively from poor to rich countries.

\section{Conclusions}

Let's agree that the treatment of human capital in development accounting should be based on an assumption of imperfect substitution between workers with different educational attainment, as advocated by Caselli and Coleman (2006), Caselli and Ciccone (2013), and Jones (2014). In this case, the cross-country data on educational wage premia implies that the relative efficiency of more educated workers is higher in rich countries than in poor countries for plausible values for the elasticity of substitution between workers with differ-

ent educational attainment. What does this imply for the contribution of human capital to cross-country income differences?

We have shown that this depends on how we interpret the relative efficiency of skilled 
workers. If we interpret relative efficiency as solely reflecting attributes of workers, and thus human capital, then development accounting with imperfect substitution implies that human capital plays a larger role than in "traditional" development accounting, as claimed by Jones. If, however, we interpret cross-country differences in the relative efficiency of skilled workers as reflecting the institutions, technology, organizational structures, infrastructure, social norms, etc. of countries, then the role of human capital is even smaller under imperfect substitution than in the perfect substitution case - the opposite of Jones's result. Hence, our exercise underscores why the definition of human capital has profound implications for development policies.

Only further research on the determinants of the high relative efficiency of skilled workers in rich countries can clarify the nature of relative efficiency differences. Meanwhile, the virtual absence of skilled migration from rich to poor countries appears to be a challenge to the view that skilled efficiency units are (portable) human capital.

\section{Appendix}

\section{A Many Skill Types}

In this appendix we show how the logic of Sections II and VI extends to the case where there are many different types of skilled workers. 
Jones's generalized labor aggregator is

$$
\begin{aligned}
& H^{c}=\left[\left(H_{1}^{c}\right)^{\frac{\varepsilon-1}{\varepsilon}}+\left(Z^{c}\right)^{\frac{\varepsilon-1}{\varepsilon}}\right]^{\frac{\varepsilon}{\varepsilon-1}} \\
& H_{1}^{c}=h_{1}^{c} L_{1}^{c} \\
& Z^{c}=Z\left(h_{2} L_{2}, \ldots, h_{N} L_{N}\right)
\end{aligned}
$$

where $L_{1}$ is the fraction of the labor force that is unskilled (workers who completed primary schooling or less), and $L_{2}, \ldots, L_{N}$ denote the fractions of skilled workers of different types (some secondary, completed secondary, etc.). The $h$ s are the corresponding efficiency units. The function $Z$ is assumed to have positive first derivatives, and to be concave and linearly homogenous.

In Section II we considered the experiments of changing a poor country's $L$ s to the levels of a rich country, with and without a simultaneous analogous change in the $h \mathrm{~s}$. To address these experiments in the multi-type framework, consider a generic change of $H_{1}^{c}$ and $Z$ to new values $\hat{H}_{1}^{c}$ and $\hat{Z}$ (this could be due to a change in the $L$ s only or in both the $L$ s and the $h \mathrm{~s})$. The corresponding new level of $H^{c}$ is $\hat{H}^{c}$. Clearly we can write

$$
\begin{aligned}
\frac{\hat{H}^{c}}{H^{c}} & =\left[\frac{\left(\frac{\hat{H}_{1}^{c}}{H_{1}^{c}}\right)^{\frac{\varepsilon-1}{\varepsilon}}+\left(\frac{\hat{Z}^{c}}{H_{1}^{c}}\right)^{\frac{\varepsilon-1}{\varepsilon}}}{1+\left(\frac{Z^{c}}{H_{1}^{c}}\right)^{\frac{\varepsilon-1}{\varepsilon}}}\right]^{\frac{\varepsilon}{\varepsilon-1}} \\
& =\left[\frac{\left(\frac{\hat{H}_{1}^{c}}{H_{1}^{c}}\right)^{\frac{\varepsilon-1}{\varepsilon}}+\left(\frac{\hat{Z}^{c}}{Z^{c}}\right)^{\frac{\varepsilon-1}{\varepsilon}}\left(\frac{Z^{c}}{H_{1}^{c}}\right)^{\frac{\varepsilon-1}{\varepsilon}}}{1+\left(\frac{Z^{c}}{H_{1}^{c}}\right)^{\frac{\varepsilon-1}{\varepsilon}}}\right]^{\frac{\varepsilon}{\varepsilon-1}} .
\end{aligned}
$$

From this equation we see that, given a value of $\varepsilon$, we can compute the change in $H^{c}$ 
associated with known percentage changes in $H_{1}^{c}$ and $Z$ if we can calibrate the quantity $\left(Z^{c} / H_{1}^{c}\right)^{(\varepsilon-1) / \varepsilon}$

It is possible to do this using relative wage data. In particular, we can still define the skill premium as the average wage earned by skilled workers (workers with attainment $2,3, \ldots$, $N)$ divided by the average wage of unskilled workers. The average wage of skilled workers, which we denote $w_{Z}$, is

$$
\begin{aligned}
w_{Z} & =F_{H}^{c} H_{Z}^{c} \sum_{i=2}^{N} Z_{i}^{c} h_{i}^{c} l_{i}^{c} \\
& =F_{H}^{c} H_{Z}^{c} \frac{Z^{c}}{\sum_{j=2}^{N} L_{j}^{c}}
\end{aligned}
$$

where $l_{i}^{c}=L_{i}^{c} / \sum_{j=2}^{N} L_{j}^{c}$ is the fraction of skilled workers of type $i=2, \ldots N ; F_{Z}^{c}$ is the derivative of the aggregate production function with respect to $H^{c} ; H_{Z}^{c}$ is the derivative of $H^{c}$ with respect to $Z ; Z_{i}^{c}$ is the derivative of $Z$ with respect to $h_{i} L_{i}$; and all derivatives are evaluated at country $c$ quantities. The first equality follows from the assumption that workers of type $i$ will be paid their marginal productivity, and the second equality follows from homogeneity of degree 1 of $Z$.

Using the functional form in (9) the skill premium then is

$$
\frac{w_{Z}}{w_{1}}=\left(\frac{Z^{c}}{h_{1} L_{1}}\right)^{-\frac{1}{\varepsilon}} \frac{Z^{c}}{\sum_{i=2}^{N} L_{i}} \frac{1}{h_{1}}
$$

which can be inverted to yield

$$
\left(\frac{Z^{c}}{H_{1}^{c}}\right)^{\frac{\varepsilon-1}{\varepsilon}}=\frac{w_{Z}}{w_{1}} \frac{\sum_{i=2}^{N} L_{i}}{L_{1}} .
$$


Now we can return to (10). In the first of our thought experiments of Section II we change only the $L \mathrm{~s}$, so $\hat{H}_{1}^{c} / H_{1}^{c}=L_{1}^{R} / L_{1}^{P}$. As for the change in $Z$, Caselli and Ciccone show that

$$
\frac{\hat{Z}^{c}}{Z^{c}} \leq \sum_{i=2}^{N} \frac{L_{i} w_{i}}{\sum_{i=2}^{N} L_{i} w_{i}} \frac{\hat{L}_{i}}{L_{i}}
$$

Putting all of the above together, we can obtain an upper bound for the change in $H^{c}$ when only the $L$ s change:

$$
\left.\frac{H^{R}}{H^{P}}\right|_{C C}=\left[\frac{w_{1}^{P} L_{1}^{P}}{\sum_{i=1}^{N} w_{i}^{P} L_{i}^{P}}\left(\frac{L_{1}^{R}}{L_{1}^{P}}\right)^{\frac{\varepsilon-1}{\varepsilon}}+\frac{\sum_{i=2}^{N} w_{i}^{P} L_{i}^{P}}{\sum_{i=1}^{N} w_{i}^{P} L_{i}^{P}}\left(\sum_{i=2}^{N} \frac{w_{i}^{P} L_{i}^{P}}{\sum_{i=2}^{N} w_{i}^{P} L_{i}^{P}} \frac{L_{i}^{R}}{L_{i}^{P}}\right)^{\frac{\varepsilon-1}{\varepsilon}}\right]^{\frac{\varepsilon}{\varepsilon-1}} .
$$

Since this expression only contains relative wages, it can be computed using the methods and data described in Section II. It is also worth mentioning that in the two skill type case $\left(Z^{c}=h_{2}^{c} L_{2}^{c}\right.$ ) this expression is exact (and not an upper bound) and reduces to equation (3).

For the thought experiment where both the $h$ s and the $L$ s change simultaneously, we can obviously use Jones's result. In particular, his equation (6) is

$$
\left.\frac{H^{R}}{H^{P}}\right|_{\text {Jones }}=\frac{h_{1}^{R}}{h_{1}^{P}}\left(\frac{L_{1}^{R}}{L_{1}^{P}}\right)^{\frac{1}{\varepsilon-1}}\left(\frac{\sum_{i=1}^{N} \frac{w_{i}^{R}}{w_{1}^{R}} L_{i}^{R}}{\sum_{i=1}^{N} \frac{w_{i}^{P}}{w_{1}^{P}} L_{i}^{P}}\right)^{\frac{\varepsilon}{\varepsilon-1}} .
$$

This can also be implemented with the data and methods developed so far, together with Jones's assumption that $h_{1}^{R}=h_{1}^{P}$ (and the expression can be treated as a lower bound if $\left.h_{1}^{R}>h_{1}^{P}\right)$.

Table 3 presents the results. The gaps in human capital computed holding efficiencies constant are now even smaller than in the two-type case, but the order of magnitude is 
Table 3: The role of relative efficiency in accounting for Jones's results with $N>2$

Elasticity of Substitution

\begin{tabular}{lllllll}
\hline 1.2 & 1.4 & 1.5 & 1.6 & 1.8 & 2 & $\infty$
\end{tabular}

\begin{tabular}{lccccccc}
$H^{85} / H^{15}$ from (11) & 0.66 & 0.69 & 0.70 & 0.72 & 0.74 & 0.75 & 0.97 \\
$H^{85} / H^{15}$ from (12) & 358 & 21.9 & 12.5 & 8.6 & 5.4 & 4.1 & 1.3 \\
\hline \hline
\end{tabular}

"Human capital" ratios between countries at $85^{\text {th }}$ and $15^{\text {th }}$ percentiles of the income distribution using only the relative-supply effect (top row) and both the relative-supply and relative-efficiency effects (bottom row). This table differs from the corresponding table in the text in that it considers the case with more than two types of workers.

roughly similar. ${ }^{17}$ The gaps predicted by the Jones approach are obviously identical to the ones in his Table 2. As already noted these are very close to the ones we obtained for the two-type case in the main text. The upshot is that the conclusions we drew from our Table 1 in the main text remain valid in the case with many types of skilled workers.

Turning to the question of Section VI, namely the gains from skill migration from country $R$ to country $P$, the exercise now consists of imagining a representative group of (heterogenous) rich country skilled workers moving to the poor country, and working there at the local wages for workers with their skill type and human capital. These workers' average wage will be

$$
\sum_{i=2}^{N} w_{i}^{P} h_{i}^{R} l_{i}^{R}=F_{Z}^{P} \sum_{i=2}^{N} Z_{i}^{P} h_{i}^{R} l_{i}^{R}
$$

where $w_{i}^{c}$ is now the wage per unit of human capital earned by a worker with skill type $i$ in country $c ; F_{Z}^{c}$ is the derivative of the aggregate production function with respect to $Z$ and

\footnotetext{
${ }^{17}$ The reason why (11) drops below unity for $\varepsilon=\infty$ is that Jones's data yields some negative skill premia when the full detail of educational attainment groups is considered. The reason why (11) drops further below unity for $\varepsilon<1$ is that assigning the relative supply of skilled and unskilled workers of rich countries to poor countries would lead to even lower skill premia. As mentioned in footnote 4, the human-capital ratios for $\varepsilon<1$ in the first row of the table would be larger if workers of type $i$ could do jobs done by less-skilled workers and were as productive as less-skilled workers in doing these jobs. However, our calculations assume that workers of type $i$ are restricted to do type- $i$ jobs for simplicity.
} 
$Z_{i}^{c}$ is the derivative of $Z$ with respect to $h_{i} L_{i}$, both evaluated at country $c$ quantities; and $l_{i}^{c}=L_{i}^{c} / \sum_{j=2}^{N} L_{j}^{c}$

Concavity of $Z$ implies

$$
\sum_{i=2}^{N} Z_{i}^{P}\left(h_{i}^{R} l_{i}^{R}-h_{i}^{P} l_{i}^{P}\right) \geq Z\left(h_{2}^{R} l_{2}^{R}, \ldots, h_{N}^{R} l_{N}^{R}\right)-Z\left(h_{2}^{P} l_{2}^{P}, \ldots, h_{N}^{P} l_{N}^{P}\right)
$$

Since $Z$ is also homogenous of degree 1 , we have $\sum_{i=2}^{N} Z_{i}^{P} h_{i}^{P} l_{i}^{P}=Z\left(h_{2}^{P} l_{2}^{P}, \ldots, h_{N}^{P} l_{N}^{P}\right)$, so the last two expressions can be combined to find

$$
\sum_{i=2}^{N} w_{i}^{P} h_{i}^{R} l_{i}^{R} \geq F_{Z}^{P} Z\left(h_{2}^{R} l_{2}^{R}, \ldots, h_{N}^{R} l_{N}^{R}\right)
$$

Note that $Z\left(h_{2}^{R} l_{2}^{R}, \ldots, h_{N}^{R} l_{N}^{R}\right)$ can be interpreted as the average human capital of skilled workers in the rich country. The average wage of this group if they stay in the rich country is $F_{Z}^{R} Z\left(h_{2}^{R} l_{2}^{R}, \ldots, h_{N}^{R} l_{N}^{R}\right)$. Therefore, the lower bound for the average wage in the destination country relative to the country of origin of a representative group of skilled workers moving from the rich to the poor country is identical to the lower bound for skilled workers making the same move in the model with a single type of skilled worker in the main text. The only difference is that $H_{2}$ is replaced by $Z$.

If we further follow Jones and pick the aggregate production function in (6), the calibration and quantitative implementation are also identical to those of Section VI. Hence, Table 2 in the main text can be interpreted as showing the wage gains or losses for a representative group of skilled workers moving from a rich to a poor country. 


\section{References}

Acemoglu, Daron (2003). "Patterns of Skill Premia." The Review of Economic Studies, 70(2), pp. 199-230.

Autor, David H., Lawrence F. Katz, and Melissa S. Kearney (2008). "Trends in US Wage Inequality: Revising the Revisionists." The Review of Economics and Statistics, 90(2), pp. $300-323$.

Caselli, Francesco (2005). “Accounting for Cross-Country Income Differences," in Philippe Aghion and Stephen Durlauf (eds.), Handbook of Economic Growth, Volume 1A, Elsevier.

Caselli, Francesco (2017). "Technology Differences over Space and Time," Princeton University Press.

Caselli, Francesco and Antonio Ciccone (2013). "The Contribution of Schooling in Development Accounting: Results from a Nonparametric Upper Bound," Journal of Development Economics, 104(1), pp. 199-211.

Caselli, Francesco and John Coleman (2006). "The World Technology Frontier," American Economic Review, 96(3), pp. 499-522.

Hall, Robert and Charles Jones, (1999). "Why Do Some Countries Produce So Much More Output Per Worker Than Others?" Quarterly Journal of Economics, 114, pp. 83-116.

Hendricks, Lutz (2002): "How Important Is Human Capital for Development? Evidence from Immigrant Earnings," American Economic Review, 92(1), pp. 198-219.

Hendricks, Lutz, and Todd Schoelmann (2017): "Human Capital and Development Accounting: New Evidence from Wage Gains at Migration," Quarterly Journal of Economics.

Jones, Benjamin (2014). "The Human Capital Stock: A Generalized Approach," Amer- 
ican Economic Review, 104(11), pp. 3752-3777.

Katz, Lawrence F., and Kevin M. Murphy (1992). "Changes in Relative Wages, 19631987: Supply and Demand Factors." The Quarterly Journal of Economics, 107(1), pp. 35-78. Klenow, Peter, and Andres Rodriguez-Claire (1997). "The Neoclassical Revival in Growth Economics: Has It Gone Too Far?" in Ben Bernanke and Julio Rothenberg (eds.), NBER Macroeconomics Annual, MIT Press.

Krusell, Per, Lee E. Ohanian, José-Víctor Ríos-Rull, and Giovanni L. Violante. "CapitalSkill Complementarity and Inequality: A Macroeconomic Analysis." Econometrica, 68(5), 1029-1053.

Machin, Stephen, and John Van Reenen (1998). "Technology and Changes in Skill Structure: Evidence from Seven OECD Countries". The Quarterly Journal of Economics, 113(4), pp. $1215-1244$.

Malmberg, Hannes (2018). "How does the efficiency of skilled labor vary across rich and poor countries? An analysis using trade and industry data," unpublished, Stanford University.

Nelson, R. and Phelps, E. (1966). Investment in humans, technological diffusion, and economic growth. American Economic Review: Papers and Proceedings, 61, 69-75.

Nunn, Nathan (2007). "Relationship-Specificity, Incomplete Contracts and the Pattern of Trade," Quarterly Journal of Economics, 122(2), pp. 569-600

Schoellman, Todd (2012). "Education Quality and Development Accounting," Review of Economic Studies, 79(1), pp. 388-417. 